Article

\title{
A New Climate Change Analysis Parameter: A Global or a National Approach Dilemma
}

\author{
Nerea Portillo Juan* $*$, Vicente Negro Valdecantos and José María del Campo (D) \\ Environment, Coast and Ocean Research Laboratory, Universidad Politécnica de Madrid, Campus Ciudad \\ Universitaria, Calle del Profesor Aranguren 3, 28040 Madrid, Spain; vicente.negro@upm.es (V.N.V.); \\ josemaria.delcampo@upm.es (J.M.d.C.) \\ * Correspondence: nportillojuan@gmail.com; Tel.: +34-636-140-134
}

Citation: Portillo Juan, N.; Negro Valdecantos, V.; del Campo, J.M. A New Climate Change Analysis Parameter: A Global or a National Approach Dilemma. Energies 2022, 15, 1522. https://doi.org/10.3390/ en15041522

Academic Editor: Cristiana Doina Tudor

Received: 31 December 2021 Accepted: 14 February 2022 Published: 18 February 2022

Publisher's Note: MDPI stays neutral with regard to jurisdictional claims in published maps and institutional affiliations.

Copyright: (C) 2022 by the authors. Licensee MDPI, Basel, Switzerland. This article is an open access article distributed under the terms and conditions of the Creative Commons Attribution (CC BY) license (https:// creativecommons.org/licenses/by/ $4.0 /)$.

\begin{abstract}
Climate change is an issue nowadays present in almost all of the media daily, but information can be manipulated very easily. It is a fact that, in the last decades, greenhouse gas emissions have multiplied, and to tackle climate change efficiently, it is necessary to analyze their origin and their relationship with regards to countries, population, production, etc. When analyzing a country's emissions, not only the total emissions, but also the emissions in relation to its population, production, etc., should be considered. In this paper, a new parameter $\left(\mathrm{CE}_{2} \mathrm{~N}\right)$ that merges total emissions, and emissions per capita and per GDP is proposed and applied, obtaining, for the first time, a unified and universal parameter that considers the emission efficiency and total emissions at the same time and can be used in all countries. We validated this new parameter with its implementation in previous environmental models, and the results obtained showed that $\mathrm{CE}_{2} \mathrm{~N}$ would help to increase the transparency and objectivity of these models, giving more weight to emission efficiency, rather than other, more subjective criteria previously used. In addition, $\mathrm{CE}_{2} \mathrm{~N}$ could be implemented in future international agreements, being beneficial not only for the scientific community, but also for policymakers.
\end{abstract}

Keywords: climate change; international agreements; countries emissions; greenhouse gases; emissions per capita; emissions per gross domestic product; new environmental parameter; sustainable policies; climate emergency; COP results

\section{Introduction}

Defining climate and climate change is a complex issue that requires study and meditation (Todorov, 1986 [1] and Werndl, 2016 [2]). The correct definition of climate change is crucial for both, climate policies and scientific studies. In fact, there are whole papers that deal with the problem of climate and climate change definition. Werndl, 2016 [2] stated that the definition of climate has to meet five conditions: be empirically and mathematically valid, classify different climates, not depend on human knowledge, and be applicable to the past, present, and future. He gave five definitions of climate and discussed their advantages and inconveniences. Lorenz already defined climate change mathematically in 1970 [3]. Werndl, 2016 [2] and Dymnikov and Gritsoun, 2001 [4] stated that there is climate change when there are different distributions of climate variables for two successive time periods. More recently, the United Nations Framework Convention on Climate Change (UNFCC) defined climate change as "a change of climate which is attributed directly or indirectly to human activity that alters the composition of the global atmosphere and which is in addition to natural climate variability observed over comparable time periods" [5], and the IPCC defined climate change as "a change in the state of the climate that can be identified by changes in the mean and/or the variability of its properties and that persists for an extended period, typically decades or longer" [6].

Climate change has always existed, since the origin of the Earth, $4500 \mathrm{M}$ years ago. However, almost all literature about climate change and global warming only focuses 
on the last few decades. Although it is true that climate change has been influenced for a long time since the agricultural revolution $[7,8]$, the main factors responsible for it are greenhouse gas (GHG) emissions, and it is has been after the industrial revolution that the amount of GHGs emitted to the atmosphere increased considerably. Between 1750 and 2011, cumulative anthropogenic $\mathrm{CO}_{2}$ emissions to the atmosphere were $2040 \pm 310 \mathrm{GtCO}_{2}$, and about half of these emissions have occurred in the last 40 years. The total anthropogenic GHG emissions continued to increase between 1970 and 2010, with the largest absolute increases occurring in the last decades. In fact, each of the last three decades has been successively warmer at the Earth's surface than any previous decade since 1850. Combined and globally averaged land and ocean surface temperature data, calculated from a linear trend, show a warming of 0.85 (0.65 to 1.06) ${ }^{\circ} \mathrm{C}$ over the period of $1880-2012$. This increase in emissions has not only produced the warming of the planet, but it has also altered ecosystems, provoked the acidification of the ocean, the death of animal species, etc. [9].

Emissions vary per country and understanding the contribution of each country to climate change is essential to face it. However, there is still no agreement on the criteria that should be used to judge countries' environmental policies, whether by total emissions, emissions per capita, or emissions per gross domestic product (GDP).

Reducing GHG emissions is directly related to Sustainable Development Goals (SDG). SDG were adopted in 2015 in the Agenda 2030 by the General Assembly of the United Nations (UN) [10,11]. Reducing GHG emissions is considered in SDG 13: Climate Action, which is positively correlated with SDG 7: Affordable and Clean Energy [11]. The literature about emissions, sustainable development goals, and energy is very rich. Among others, Bilan et al. [12], Zoundi [13], and Liu et al. [14] studied it and concluded that the use of renewable energy allowed decreasing the emissions of GHG. Ziolo et al. [15] and Akaev et al. [16] supported the need to increase energy efficiency and to develop a good energy transition if sustainable development is to be reached. Peña-Ramos et al. [17] studied the energy transition in Spain. Drozdz et al. [18] studied the determinants of decarbonization and of the development of a sustainable energy system in Poland, and Zimon et al. [19] studied the relationship between emissions, SDG, business models, and supply chains.

There are also many scientific articles about GHG emissions, their impact on the economy, energy, and population, their spatial distribution, and the relationship between all of these variables. In fact, the study of the linkage between economic growth and emissions goes back to the 1990s, with Grossman and Krueger [20,21] and Douglas [22].

Some of the most relevant studies about the distribution of GHG emissions, population, and GDP are the following: Zhang et al. [23] studied the advantages and drawbacks of using each variable (total emissions, emissions per capita, and emissions per GDP) as an indicator. Moghaddam et al. [24] proposed a new GHG intensity indicator that integrated the concepts of GDP and per capita in a new one that they called activities. Liang et al. [25] carried out an analysis of the emissions of each nation. Arango Miranda et al. [26] analyzed the relationship between carbon dioxide $\left(\mathrm{CO}_{2}\right)$ emissions, energy consumption, and economic growth. Sun et al. [27] developed an index that incorporated the concepts of ecology, economy, and equity to analyze the spatial distribution of emissions in China. Leitão et al. [28] studied the linkage between emissions, economic growth, tourism, and renewable energy in the European Union. Bădîrcea et al. [29] studied the relationship between climate change, emissions, and the blue economy, and Karman et al. [30] presented a climate model to evaluate regional competitiveness.

All these previous studies either conducted complex environmental models on specific areas/countries, or analyzed only some of the three main parameters to be considered when talking about emissions (population, GDP, and total emissions). However, none of them proposed neither a universal formula that could be applied to every country of the world, nor a formula that integrated GDP, population, and total emissions in only one parameter. This paper proposes a new universal formula to quantify emissions that integrates these three main variables in a unique parameter: $\mathrm{CE}_{2} \mathrm{~N}$ (where $C$ means carbon dioxide, $E$ means equivalent, and $N$ means normalized). 
The main objective of this study is to define a universal criterion that puts an end to disputes about what should be the environmental variable (total emissions, or emissions per capita or per GDP) that underlies international agreements, unifying the variables used until now into a single $\mathrm{CE}_{2} \mathrm{~N}$ parameter that can also be applied in environmental models developed by the scientific community. The results of environmental models vary a lot depending on the criteria used and, as $\mathrm{CE}_{2} \mathrm{~N}$ unifies all these criteria, it will end with this problem.

For the first time in the literature, a global parameter that unifies the three main environmental variables and that can be applied in every country of the world, not only in some countries or specific areas, is proposed.

The uniqueness of the study lies in the fact that it proposes a unified and simple criterion that can benefit both politicians and the scientific community, helping to narrow the gap between science and society and making the understanding of emissions distribution accessible to everyone. $\mathrm{CE}_{2} \mathrm{~N}$ is very simple and has an advantage over other studies-its clarity. There is no need to use sophisticated and unclear equations to obtain $\mathrm{CE}_{2} \mathrm{~N}$, although it can also be implemented in more complex models (Section 4.3.2), also making environmental models more objective.

The limitations of the technique applied in this study are that the allocation of the total emissions, emissions per capita, and per GDP weights depends on user criteria (Section 3.2 Weighting of total emissions, emissions per capita, and per GDP), and that, to obtain $\mathrm{CE}_{2} \mathrm{~N}$, only the emissions of the present year are considered; consequently, $\mathrm{CE}_{2} \mathrm{~N}$ gives only an image of the environmental policies of a country in the present. However, historical emissions could be considered when applying $\mathrm{CE}_{2} \mathrm{~N}$ in environmental models (Section 4.3.2).

The structure of the paper is as follows: Section 2 presents the literature review; Section 3 describes the methodology; Section 4 reveals the results obtained; Section 5 presents the discussion of results and policy recommendations; and Section 6 states the conclusions reached and suggests new research lines.

\section{Literature Review}

The literature on climate change, gas emissions of nations, and equity is voluminous. Some of the most significant contributions are those made by Sagar [31], who studied the allocation scheme of emissions; Vaillancourt and Waaub [32], who developed a model to allocate emissions based on the equity principle; Markandya [33], who conducted an analysis of the distribution of climate change; Mattoo and Subramanian [34], who conducted a review about equity and climate change; Remuzgo et al. [35], who studied the evolution of GHG emissions during 1990-2011; Alcaraz et al., who developed a model of climate justice per capita [36] and applied it to the Mediterranean [37]; and Jena et al. [38], who designed a nonlinear model to forecast the $\mathrm{CO}_{2}$ emissions of the 17 key emitting countries.

There are three main approaches in the study of the distribution of gas emissions and equity $[33,34]$ :

- $\quad$ Emissions per capita: Based on the principle that every person has an equal right to emit GHG. There are some authors that support this approach, such as Dubash, N.K. [39], Saran, S. [40], and Alcaraz et al. [36]. However, judging environmental responsibility focusing on emissions per capita is far from equity, because the capacity to produce GHG and also to reduce emissions highly depends on the level of development of a country [41-43]. In addition, the main percentage of GHG emissions is not caused by individuals;

- Emissions per GDP: Supported by Cao, J. [44], among others. Based on the idea that countries with higher levels of production have the right to emit more GHG, but, as it happens with the emissions per capita scope, this theory helps to increase the gap between high and low-income countries;

- Historic responsibility: Dubash, N.K. [39], Cooper, R. N. [45], and Stern, N. [46] are some of the authors that agree with this scope. It considers that the allocation of future emissions should be inversely related to past emissions. However, it is not clear from 
when emissions should be accounted from. Although many authors consider that it should be since the industrial revolution (Cao, J. [44], Kanitkar et al. [47]), humankind has been altering the climate since the origin of the human species and not only over the last 100 years, so it would not be rigorous to only consider a few years. However, as stated by Shue [48], emissions from developing countries should be treated differently to those from developed countries; the latter should support developing countries with their adaptation costs, mainly through financial and technological transfers (Falkner [49]).

The fact that the emissions per capita and per GDP approaches are not fair is supported by the Environmental Kuznets Curve Theory [50], which states that the emissions of $\mathrm{CO}_{2}$ follow an inverted U-shape with economic growth. Therefore, the level of emissions of a country will depend on its level of development. The literature on this topic is very abundant. Some of the most recent and relevant studies were carried out by Dogan et al. [51], Mania et al. [52], Jóźwik et al. [53], and Knight and Schor [54].

The relationship between globalization and GHG emissions has also been studied, but there are no solid conclusions. Some studies, such as the ones carried out by Rahman [55], Villanthenkodath et al. [56], and Baydoun et al. [57], concluded that globalization helps to reduce GHG emissions, while others, such as the ones by Pata, U.K. [58] or Kihombo et al. [59], concluded the opposite.

Similar to globalization, there are no strong conclusions linking financial development and emissions. Some studies defend a negative relationship ( $\mathrm{Xu}$ et al. [60] and Salahuddin et al. [61]), while others support a positive relationship (Chebbi et al. [62], Jiang and Ma [63], and Ameyaw and Lao. [64]).

\section{International Agreements, Kyoto, and Paris}

In order to tackle the problem of climate change, it is essential to study the international agreements that have been reached throughout history and the political and social situation. This is the main rationale for this section.

In 1992, climate change was recognized as a problem for the first time, when the UNFCC was adopted [65]. Since then, 26 conferences have taken place and two big international agreements have been adopted: the Kyoto Protocol and the Paris Agreement [66-68].

The Kyoto Protocol was adopted in 1997; it was the first international agreement in which nations committed to reducing their emissions by $5 \%$ (referring to 1990 emissions) for the period of 2008-2012. However, the Kyoto Protocol distinguished between developed and developing countries. Only developed countries who were annexed in UNFCC had quantified commitments, while developing countries only had to try to improve their policies. In addition, the Kyoto Protocol defined different tools to help nations to reach their targets [66]:

- International Emissions Trading: Based on the right of emitting gases and its commercialization. When a country reduces its emissions in a percentage higher than its target, it can sell the surplus of $\mathrm{CO}_{2}$ on the carbon market;

- Clean Development Mechanism (CDM): It allows an annexed country to implement an emission-reduction project on developing countries. Such projects can earn saleable certified emission reductions, which can be counted towards meeting reduction targets [69];

- Joint Implementation (JI): It allows an annexed country to earn emission reduction units from an emission-reduction or emission removal project in another annexed country [70].

In 2012, the Kyoto Protocol was extended until 2020 with the Doha Amendment. Countries that ratified it committed to reducing their emissions by $18 \%$ for 2020 . However, the Doha Amendment never entered into force because the annexed countries only represented $15 \%$ of global emissions $[66,67]$.

The other big international agreement is the Paris Agreement that came into effect in 2016. It leaves the distinction between developed and developing countries and also 
the common objective of reducing the emissions by a certain percentage. With this new agreement, each country has to commit to making its best effort to develop environmental policies through nationally determined contributions [68].

\section{Materials and Methods}

The new parameter proposed, $\mathrm{CE}_{2} \mathrm{~N}$, is obtained by applying the following equation:

$$
\begin{gathered}
\mathrm{CE}_{2} \mathrm{~N}\left[\text { units of normalized } \mathrm{CO}_{2}\right] \\
=\alpha \mathrm{CO}_{2}[\mathrm{Mt} / \text { year }]+\beta \mathrm{CO}_{2} \text { per capita }[\mathrm{t} / \text { year }]+\gamma \frac{\mathrm{CO}_{2}}{\mathrm{kUSD}}[\mathrm{t} / \text { year }]
\end{gathered}
$$

where $\alpha, \beta$, and $\gamma$ are constants that are obtained by normalizing and weighting each variable.

\subsection{Normalization of Total Emissions, Emissions Per Capita, and Per GDP}

As the total emissions, and emissions per capita and per GDP have different orders of magnitude, the first step is to normalize them. To this end, the maximum and minimum values of each variable are studied.

The emissions per capita is the variable that has medium values (total emissions are usually higher than the emissions per capita and the emissions per GDP are usually lower). Therefore, the constant of the emissions per capita $\beta$ is taken as the base parameter. As $\beta$ is taken as the reference value, $\beta$ is equal to 1 .

\subsubsection{Normalization of Total Emissions $(\alpha)$}

- Total emissions are, on average, 41 times the emissions per capita;

- About $90 \%$ of the total emissions are between 0.2 and 82 times the emissions per capita;

- Total emissions' standard deviation is 154 units.

Therefore, to make the total emissions and emissions per capita have the same order of magnitude, the total emissions' constant $\alpha$ has to be divided by 0.2 and 82 . This gives a range of values $\alpha$ of 0.012 to 5 . From this acceptable range of values, the value of 0.07 was chosen as the recommended value for $\alpha$, because it is the medium value plus $15 \%$ of deviation units, which was considered the best statistical criteria. Below, the whole process of normalization is explained step by step.

Final objective : $\alpha \times$ Total emissions $=\beta \times$ Emissions per capita

$$
\left\{\begin{array}{c}
\beta=1 \\
\text { Max. Total emissions }=82 \times \text { Emissions per capita } \\
\text { Min. Total emissions }=0.2 \times \text { Emissions per capita }
\end{array}\right.
$$

Substituting (3) and (4) in (2) gives

$\alpha \times 82 \times$ emissions per capita $=1 \times$ emissions per capita

$$
\alpha=\frac{1}{82}=0.012
$$

Substituting (3) and (5) in (2) gives

$\alpha \times 0.2 \times$ emissions per capita $=1 \times$ emissions per capita

$$
\alpha=\frac{1}{0.2}=5
$$

Range of values of $\alpha=0.012$ to 5

Average value $=41 ;$ Deviation units $=154 ; 0.15 \times$ Deviation units $=23.1$ 


$$
\alpha=\frac{1}{41}+\frac{1}{23.1}=0.07
$$

3.1.2. Normalization of the Emissions per $\operatorname{kUSD}(\gamma)$

- $\quad$ Emissions per kUSD are, on average, 1/21 times the emissions per capita;

- About $90 \%$ of the emissions per kUSD are around $1 / 3$ and $1 / 50$ times the emissions per capita;

- The standard deviation of emissions per kUSD is 22 units.

Taking the parameter of emissions per capita $\beta$ as the base parameter, $\gamma$ range of values should be between 3 and 50. From this range, the value of 23 was chosen as the recommended value for $\gamma$ because it is the medium value of the range proposed plus $10 \%$ of the deviation units, which was considered the best statistical criteria. (Same criteria as those applied to total emissions, but with $5 \%$ fewer deviation units because, for the total emissions, the standard deviation is more relevant).

Final objective : $\gamma \times$ emissions per GDP $=\beta \times$ emissions per capita

$$
\left\{\begin{aligned}
\beta & =1 \\
\text { Max. Emissions per GDP } & =\frac{1}{3} \times \text { Emissions per capita } \\
\text { Min. Emissions per GDP } & =\frac{1}{50} \times \text { Emissions per capita }
\end{aligned}\right.
$$

Substituting (7) and (8) in (6) gives

$$
\begin{gathered}
\gamma \times \frac{1}{3} \times \text { emissions per capita }=1 \times \text { emissions per capita } \\
\gamma=3
\end{gathered}
$$

Substituting (3) and (5) in (2) gives

$$
\begin{gathered}
\gamma \times \frac{1}{50} \times \text { emissions per capita }=1 \times \text { emissions per capita } \\
\gamma=50
\end{gathered}
$$$$
\text { Range of values of } \gamma=3 \text { to } 50
$$

Average value $=\frac{1}{21} ;$ Deviation units $=22 ; 0.10 \times$ Deviation units $=2.2$

$$
\gamma=21+2.2=23
$$

In the table below (Table 1 ), the values obtained for $\alpha, \beta$, and $\gamma$ after normalizing the variables are presented.

Table 1. Values of $\alpha, \beta$, and $\gamma$ after normalization.

\begin{tabular}{ccc}
\hline Constant & Range without Weight Allocation & Recommended Value of the Range \\
\hline$\alpha$ & 0.012 to 5 & 0.07 \\
$\beta$ & Base parameter (1) & Base parameter (1) \\
$\gamma$ & 3 to 50 & 23 \\
\hline
\end{tabular}

\subsection{Weighting of Total Emissions, Emissions Per Capita and Per GDP}

The second step is to assign the corresponding weight to each of the variables. It was considered that the best relative weight for the total emissions ( $\alpha$ ) was $70 \%$, and 15\% for the emissions per capita $(\beta)$ and per $\operatorname{kUSD}(\gamma)($ Table 2$)$. 
Table 2. Parameter values proposed.

\begin{tabular}{ccccc}
\hline Parameter & $\begin{array}{c}\text { Range without } \\
\text { Weight Allocation }\end{array}$ & $\begin{array}{c}\text { Recommended } \\
\text { Value of the Range }\end{array}$ & $\begin{array}{c}\text { Relative } \\
\text { Weight }\end{array}$ & $\begin{array}{c}\text { Recommended } \\
\text { Value }\end{array}$ \\
\hline $\boldsymbol{\alpha}$ & 0.012 to 5 & 0.07 & 0.7 & 0.05 \\
$\boldsymbol{\beta}$ & Base parameter (1) & Base parameter (1) & 0.15 & 0.15 \\
$\gamma$ & 3 to 50 & 23 & 0.15 & 3.50 \\
\hline
\end{tabular}

This distribution is based on the fact that the priority right now is to cut $\mathrm{CO}_{2}$ emissions. This is why the total emissions relative weight is much higher (0.7). It is based on the authors' criteria and knowledge, but if potential users of $\mathrm{CE}_{2} \mathrm{~N}$ do not agree with this distribution of weights, it can be changed. If a user considers that a better distribution would be $60 \%$ for total emissions and $20 \%$ for emissions per capita and per GDP, the new values of $\alpha, \beta$, and $\gamma$ can be obtained by multiplying the recommended value of the range (column 3 of Tables 1 and 2) by the new relative weight:

$$
\begin{gathered}
\alpha: 0.07 \times 0.6=0.04 \\
\beta: 1 \times 0.2=0.2 \\
\gamma: 23 \times 0.2=4.6 \\
\mathrm{CO}_{2} \mathrm{~N}=0.05 \mathrm{CO}_{2}+0.15 \mathrm{CO}_{2} \text { per capita }+3.5 \mathrm{CO}_{2} / \mathrm{kUSD}
\end{gathered}
$$

Once the formula was defined, it was validated by introducing it into previous environmental models. Finally, the results obtained were analyzed and compared to the results obtained from the original models (Sections 4.3.2 and 5).

\section{Results}

To analyze how the implementation of $\mathrm{CE}_{2} \mathrm{~N}$ will change international agreements and environmental models, a previous analysis of emissions statistics and of compliance with agreements needs to be presented.

Section 4.1 presents the analysis of the total emissions, and emissions per capita and per kUSD; Section 4.2 presents the analysis of the compliance of the Kyoto Protocol; Section 4.3 focuses on the new parameter, $\mathrm{CE}_{2} \mathrm{~N}$; and, finally, Section 4.4 presents different graphs to illustrate the application of $\mathrm{CE}_{2} \mathrm{~N}$.

\subsection{Total Emissions, and Emissions Per Capita and Per kUSD}

The distribution of the global total emissions in 1990 and 2019 is presented below (Figure 1).

DISTRIBUTION OF TOTAL EMISSIONS 1990

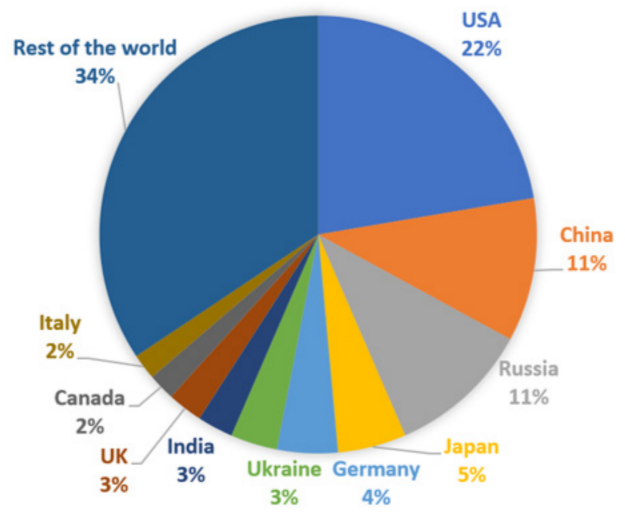

DISTRIBUTION OF TOTAL EMISSIONS 2019

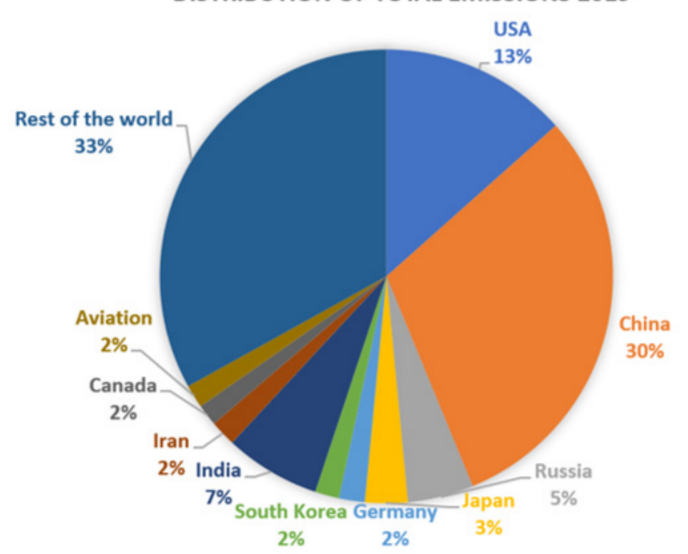

Figure 1. Distribution of global emissions 1990 vs. 2019. Own elaboration. 
Since 1990 (base year), global emissions have increased by 68\% and the world population has increased by $45 \%$, which means that, today, humanity is not only emitting more $\mathrm{CO}_{2}$, but also more $\mathrm{CO}_{2}$ per person (16\% greater than in 1990) [71]. In addition, as it can be seen from the figure above, the three most polluting countries (China, the USA, and India) account for $50 \%$ of global emissions. These three countries emit as much as the remaining 191 countries, which means that, without their collaboration, the climate change problem cannot be addressed.

The tables below show the countries that reduced and increased their emissions the most in 2019 compared to 1990 (Tables 3 and 4, where $M t$ is Megaton and $t$ is ton).

Table 3. Ten first countries with the greatest reduction in emissions. Own elaboration.

\begin{tabular}{cc}
\hline \multicolumn{2}{c}{ Max. Reduction of Emissions (Mt/Year) } \\
\hline Country & Reduction $\mathbf{1 9 9 0}$ \\
\hline EU27+UK & 1104 \\
Russia & 601 \\
Ukraine & 586 \\
Germany & 315 \\
UK & 223 \\
Romania & 108 \\
Italy & 98 \\
North Korea & 89 \\
France & 71 \\
Czechia & 57 \\
\hline
\end{tabular}

Table 4. Ten countries with the greatest increment in emissions. Own elaboration.

\begin{tabular}{cc}
\hline \multicolumn{2}{c}{ Max. Increment of Emissions (Mt/Year) } \\
\hline Country & Increment $\mathbf{1 9 9 0}$ \\
\hline China & 9130 \\
India & 1997 \\
Iran & 497 \\
Indonesia & 461 \\
Saudi Arabia & 441 \\
South Korea & 381 \\
Vietnam & 284 \\
Turkey & 265 \\
Brazil & 250 \\
Mexico & 194 \\
\hline
\end{tabular}

If, instead of the global total emissions, the emissions per capita are studied, the results are very different. China or the USA are no longer the most polluting countries, and, in the ranking of countries with the worst values of emissions per capita, new countries appear [71] (Table 5).

When the emissions per kUSD are analyzed, the results are the same as in the previous section. There are new countries that appear in the list of countries with the worst values of emissions per kUSD [71] (Table 6).

From Tables 3 and 4, it can be seen that the countries that reduced most their emissions with respect to 1990 are European, and the countries that incremented their emissions the most are China and India, two of the three most polluting countries in 2019. Tables 5 and 6 show that the countries with worst the emission efficiencies are developing countries. These two facts are related to the Environmental Kuznets Curve Theory [50] that states that the emissions of $\mathrm{CO}_{2}$ follow an inverted U-shape with economic growth. In India and China, economic growth is based on industrial development, which means increasing GHG emissions. On the other hand, European countries were already developed countries in 
1990, and their economy and technology allow them to continue growing without emitting more $\mathrm{CO}_{2}$ into the atmosphere.

Table 5. Ten countries with the worst values of emissions per capita in 1990 and 2019. Own elaboration.

\begin{tabular}{cccc}
\hline \multicolumn{2}{c}{1990} & & 2019 \\
\hline Country & $\boldsymbol{t} \mathbf{C O}_{2} /$ Capita/Year & Country & $\boldsymbol{t}$ CO $_{2} /$ Capita/Year \\
\hline Palau & 142.826 & Palau & 58.879 \\
Curaçao & 37.321 & New Caledonia & 55.25 \\
Qatar & 35.695 & Qatar & 38.823 \\
Luxembourg & 30.777 & Curaçao & 36.382 \\
United Arab Emirates & 30.601 & Trinidad \& Tobago & 23.806 \\
Estonia & 24.576 & Kuwait & 23.289 \\
Bahrain & 24.173 & United Arab Emirates & 22.992 \\
St. Pierre \& Miquelon & 23.556 & Bahrain & 21.637 \\
USA & 20.057 & Gibraltar & 19.884 \\
Canada & 16.373 & Oman & 18.549 \\
\hline
\end{tabular}

Table 6. Ten countries with the worst values of emissions per kUSD in 1990 and 2019. Own elaboration.

\begin{tabular}{cccc}
\hline & \multicolumn{1}{c}{$\mathbf{1 9 9 0}$} & \multicolumn{2}{c}{$\mathbf{2 0 1 9}$} \\
\hline Country & $\boldsymbol{t} \mathbf{C O}_{\mathbf{2}} / \mathbf{k U S D}$ & Country & $\boldsymbol{t} \mathbf{C O}_{\mathbf{2}} / \mathbf{k U S D}$ \\
\hline Palau & 10.273 & Palau & 4.089 \\
Bosnia \& Herzegovina & 3.024 & New Caledonia & 1.666 \\
Curaçao & 1.882 & Curaçao & 1.514 \\
Uzbekistan & 1.757 & Syria & 1.198 \\
Turkmenistan & 1.718 & Armenia & 1.129 \\
China & 1.488 & Turkmenistan & 0.98 \\
Estonia & 1.475 & Mongolia & 0.905 \\
Mongolia & 1.208 & Trinidad \& Tobago & 0.897 \\
Belarus & 1.203 & Barbados & 0.853 \\
Kazakhstan & 1.141 & Iran & 0.685 \\
\hline
\end{tabular}

In the table below (Table 7), the countries with the largest values of emissions and their relative position according to other variables (emissions per capita and per kUSD) are presented. It can be seen that the statistics differ a lot depending on the variable analyzed.

\subsection{Kyoto Annexed Countries Emissions}

With the aim of analyzing the effectiveness of the Kyoto Protocol and its compliance, the emissions of each annexed country in 1990 and 2019 are presented in Table 8 (the emissions are given in $M t /$ year).

As it can be seen, the Kyoto Protocol was, by far, fulfilled. The annexed countries reduced their emissions by $72 \%$ with respect to the emissions in 1990 . Twenty of 34 countries reached their objectives, which means $60 \%$ of the countries. The remaining $40 \%$ did not fulfill their promises, which can be considered a high percentage. However, $85 \%$ of the countries that did achieve their targets reduced their GHG emissions by more than $20 \%$, and some of the countries reduced their emissions by more than 50\%: Ukraine (75\%), Lithuania (61\%), and Romania (60\%) are some of these countries. This is the main reason why, despite the fact that many countries did not deliver as promised, the Kyoto Protocol did deliver, because the countries that did reduce their emissions did so at high rates. These results and their implications will be further discussed in Section 5.

The USA, Russia, Japan, New Zealand, and Canada are not included in the table because they abandoned the Kyoto Protocol before its end. 
Table 7. Position of the countries with the highest values of emissions in the emissions per capita and per kUSD in 2019. Own elaboration.

\begin{tabular}{|c|c|c|}
\hline $\begin{array}{c}\text { Countries with the } \\
\text { Highest Values of } \mathrm{CO}_{2} \\
\text { Emissions in } 2019\end{array}$ & $\begin{array}{c}\text { Relative Position among Countries with Worst } \\
\text { Values of } \\
t \mathrm{CO}_{2} / \text { Capita/Year } 2019 \\
\text { (Position } 1 \text { Would Be the Country with the } \\
\text { Highest Emissions per Capita) }\end{array}$ & $\begin{array}{c}\text { Relative Position among Countries with Worst } \\
\text { Values of } \\
t \mathrm{CO}_{2} / \mathrm{kUSD} / \text { Year } 2019 \\
\text { (Position } 1 \text { Would BE the Country with the } \\
\text { Highest Emissions per GDP) }\end{array}$ \\
\hline China & 42 & 18 \\
\hline USA & 16 & 60 \\
\hline EU27+UK & 53 & 115 \\
\hline India & 124 & 32 \\
\hline Russia & 22 & 24 \\
\hline Japan & 33 & 68 \\
\hline Germany & 37 & 108 \\
\hline Iran & 39 & 12 \\
\hline South Korea & 21 & 45 \\
\hline Indonesia & 110 & 83 \\
\hline
\end{tabular}

Table 8. Kyoto Protocol emissions analysis. Own elaboration.

\begin{tabular}{|c|c|c|c|c|}
\hline Country & $\begin{array}{c}\% \text { Emissions } \\
\text { Base Year } \\
\text { Commitment }\end{array}$ & $\begin{array}{l}\text { Base Year } \\
\text { Emissions }\end{array}$ & 2019 Emissions & $\% 2019-B a s e$ \\
\hline Germany & 80 & 1018.221 & 702.6 & 69.00 \\
\hline Australia & 99.5 & 354.23 & 433.379 & 122.34 \\
\hline Austria & 80 & 62.927 & 72.363 & 115.00 \\
\hline Belgium & 80 & 115.996 & 104.415 & 90.02 \\
\hline Bulgary * & 80 & 82.346 & 43.314 & 52.60 \\
\hline Belaruse * & 88 & 109.02 & 66.335 & 60.85 \\
\hline Cyprus & 80 & 4.54 & 7.413 & 163.24 \\
\hline Croatia * & 80 & 25.158 & 19.119 & 76.00 \\
\hline Denmark & 80 & 53.59 & 31.119 & 58.07 \\
\hline Slovakia * & 80 & 60.545 & 35.985 & 59.44 \\
\hline Slovenia * & 80 & 16.624 & 15.365 & 92.43 \\
\hline Spain & 80 & 230.354 & 259.31 & 112.57 \\
\hline Estonia * & 80 & 38.468 & 18.503 & 48.10 \\
\hline Finland & 80 & 57.254 & 43.415 & 75.83 \\
\hline France and Monaco & 80 & 386.367 & 314.736 & 81.46 \\
\hline Greece & 80 & 79.191 & 65.568 & 82.80 \\
\hline Hungary * & 80 & 72.075 & 53.183 & 73.79 \\
\hline Ireland & 80 & 32.904 & 36.548 & 111.07 \\
\hline Iceland & 80 & 2.357 & 3.925 & 166.53 \\
\hline Italy & 80 & 430.061 & 331.563 & 77.10 \\
\hline Kazakhstan & 95 & 251.29 & 277.365 & 110.38 \\
\hline Latvia * & 80 & 20.132 & 8.379 & 41.62 \\
\hline Lithuania * & 80 & 35.305 & 13.772 & 39.01 \\
\hline Luxembourg & 80 & 11.75 & 9.74 & 82.89 \\
\hline Norway & 80 & 37.324 & 47.991 & 128.58 \\
\hline Holland & 80 & 161.195 & 156.415 & 97.03 \\
\hline Poland * & 80 & 371.381 & 317.654 & 85.53 \\
\hline Portugal & 80 & 43.692 & 48.472 & 110.94 \\
\hline $\begin{array}{c}\text { United Kingdom and } \\
\text { North Ireland }\end{array}$ & 80 & 588.068 & 364.906 & 62.05 \\
\hline Czech Republic* & 80 & 162.835 & 78.631 & 48.29 \\
\hline Romania * & 80 & 187.291 & 78.631 & 41.98 \\
\hline
\end{tabular}


Table 8. Cont.

\begin{tabular}{ccccc}
\hline Country & $\begin{array}{c}\text { \% Emissions } \\
\text { Base Year } \\
\text { Commitment }\end{array}$ & $\begin{array}{c}\text { Base Year } \\
\text { Emissions }\end{array}$ & 2019 Emissions & \% 2019-Base \\
\hline $\begin{array}{c}\text { Sweden } \\
\text { Switzerland and }\end{array}$ & 80 & 58.104 & 44.749 & 77.02 \\
Liechtenstein & 84.2 & 44.955 & 39.371 & 87.58 \\
Ukraine * & 80 & 783.21 & 196.401 & $\mathbf{2 5 . 0 8}$ \\
Total & $\mathbf{8 2}$ & & & 72 \\
\hline
\end{tabular}

Countries with "** are countries that were considered by Kyoto Protocol as developing countries, so they did not have real commitments, they only had to try to develop sustainable policies. Countries with the \%2019-base in green are countries that fulfilled their commitment, and countries with this number in red are countries that did not.

\section{3. $C E_{2} N$}

As the results differ a lot depending on the variable analyzed, the formula presented in the section "Methodology" has been proposed in order to integrate all variables in one parameter: $\mathrm{CE}_{2} \mathrm{~N}$. This new parameter $\mathrm{CE}_{2} \mathrm{~N}$ aims to define a unique classification of the most polluting countries and also proposes a unified criterion that could be applied in environmental models. $\mathrm{CE}_{2} \mathrm{~N}$ considers all the variables (GDP, population, and total emissions), and not just one of them. It is important to consider the total emissions, GDP, and population in one parameter to account for different factors and to be more impartial when assessing countries' environmental policies.

Configuring $\mathrm{CE}_{2} \mathrm{~N}$ with $\alpha=0.05, \beta=0.15$ and $\gamma=3.5$, the obtained classification of the 20 most-polluting countries for the year 2019 would be as follows (Table 9):

Table 9. $\mathrm{CE}_{2} \mathrm{~N}$ Classification.

\begin{tabular}{cc}
\hline Country & $\mathbf{C E}_{\mathbf{2}} \mathbf{N}$ \\
\hline China & 579.77045 \\
USA & 258.5589 \\
EU27+UK & 166.67385 \\
India & 131.4827 \\
Russia & 93.05085 \\
Japan & 59.8236 \\
Germany & 38.7682 \\
Iran & 36.95795 \\
South Korea & 35.53405 \\
Saudi Arabia & 34.76765 \\
Canada & 32.705 \\
Indonesia & 32.3173 \\
South Africa & 28.9105 \\
Mexico & 25.47545 \\
Australia & 25.46055 \\
Brazil & 24.7873 \\
Palau & 23.20985 \\
Turkey & 22.16045 \\
United Kingdom & 19.4723 \\
Kazakhstan & 18.09745 \\
\hline
\end{tabular}

If the $\mathrm{CE}_{2} \mathrm{~N}$ classification is compared with the total emissions classification per country, the results are as follows (in red are those countries that change their position in the ranking) (Table 10). 
Table 10. Twenty top emitters countries and differences with the $\mathrm{CE}_{2} \mathrm{~N}$ classification. Own elaboration.

\begin{tabular}{cc}
\hline Country & Mt/Year \\
\hline China & 11535 \\
USA & 5107.2 \\
EU27+UK & 3303.9 \\
India & 2597.3 \\
Russia & 1792.0 \\
Japan & 1153.7 \\
Germany & 702.6 \\
Iran & 701.98 \\
South Korea & 651.87 \\
Indonesia & 625.66 \\
Saudi Arabia & 614.60 \\
Canada & 584.84 \\
South Africa & 494.86 \\
Mexico & 485.00 \\
Brazil & 478.14 \\
Australia & 433.37 \\
Turkey & 415.78 \\
United Kingdom & 364.90 \\
Italy, Vatican City and S.Marino & 331.56 \\
Poland & 317.65 \\
\hline
\end{tabular}

As per the table, $\mathrm{CE}_{2} \mathrm{~N}$ gives a new methodology to assess countries' emissions; considering the emissions per capita and per GDP changes the usual classification.

Comparing Tables 9 and 10, it can be seen that using $\mathrm{CE}_{2} \mathrm{~N}$ narrows the emissions gap between countries. While the difference in the total emissions between China and USA is $6428 \mathrm{Mt}$, it is 321 in equivalent carbon units. In fact, from the eighth position, the $\mathrm{CE}_{2} \mathrm{~N}$ differences between countries are less than 1 equivalent carbon unit (Table 9), while those in Table 10 are more than $100 \mathrm{Mt}$. This implies that countries that change their environmental policies and make an effort to improve their emissions statistics can easily change their position in the $\mathrm{CE}_{2} \mathrm{~N}$ Classification (Table 9), while it would be much more difficult in the usual classification (total emissions, Table 10). Therefore, using $\mathrm{CE}_{2} \mathrm{~N}$ as the new reference environmental parameter could promote the improvement of environmental policies, as it would be much easier to see direct results than with the previous environmental criteria. However, as will be explained in Section 4.3.1 and in Section 5, the position of the top eight emitting countries is very difficult to change due to their high level of total emissions.

\subsubsection{Sensitivity Analysis}

The $\mathrm{CE}_{2} \mathrm{~N}$ formula is a formula that integrates the concept of total emissions, emissions per capita, and emissions per GDP with the aim of knowing how polluting a country is. The sensitivity of this formula depends on the values of the parameters chosen. A sensitivity analysis with the recommended values of the parameters for two scenarios was conducted:

- Scenario 1: Europe continues with its policy of reducing its total emissions, reaching an $8 \%$ of reduction, and Asia and America continue increasing their emissions with an increment of $5 \%$.

- Scenario 2: Most developed countries reduce their emissions by $5 \%$ and developing countries increase their emissions by $5 \%$.

Total emissions sensitivity

For both scenarios, the formula was "highly sensitive" to the total emissions. However, the position of the 10 countries with the highest values of emissions hardly changed due to their high values of emissions. The difference in the amount of gases emitted by the 10 most emitting countries was large. For example, China emits $6428 \mathrm{Mt}$ of $\mathrm{CO}_{2}$ more than the USA [71], which is a great difference that makes it very difficult to change the relative position of these countries. As emissions become lower, the difference in emissions 
between countries also decreases, which makes the formula proposed much more sensitive. The positions of the countries began to change from the ninth position.

Emissions per capita and per GDP sensitivity

With the values of the parameters proposed, the formula of $\mathrm{CE}_{2} \mathrm{~N}$ is less sensitive for the emissions per capita and per GDP than for total emissions. This is due to the reason that it was considered that the most appropriate relative weights were $70 \%$ for the total emissions and $15 \%$ for the emissions per capita and per GDP. However, if the user does not agree with this and considers that the emissions per capita and per GDP should be more important in the formula, it would be enough to use a lower value of $\alpha$ and higher values of $\beta$ and $\gamma$.

\subsubsection{Validation of the New Parameter $\mathrm{CE}_{2} \mathrm{~N}$}

In this section, $\mathrm{CE}_{2} \mathrm{~N}$ is introduced into the environmental models developed by Sagar [31] and Vaillancourt and Waaub [32].

The results obtained from the models are consistent with the changes that the introduction of the $\mathrm{CE}_{2} \mathrm{~N}$ into the models imply. Therefore, the new formula proposed for $\mathrm{CE}_{2} \mathrm{~N}$ is considered validated.

How the introduction of $\mathrm{CE}_{2} \mathrm{~N}$ changes the results of these models is analyzed in Section 5 .

Sagar, AD. (2000)

Sagar, AD. [31] developed a model to allocate future GHG emissions based on equal per capita emissions. Three factors were considered in this environmental model:

1. Population;

2. Per capita income levels (pcGNPPPP);

3. Per capita accumulative responsibility ( $\mathrm{pcCR}$ ).

The basic allocation formula proposed by Sagar is [31]:

$$
F_{i}=\frac{\operatorname{Pop}_{\mathrm{i}} \times \mathrm{f}\left(\mathrm{pcGNP}_{\mathrm{PPP}_{\mathrm{i}}}\right) / \mathrm{g}\left(\mathrm{pcCR}_{\mathrm{i}}\right)}{\sum_{\mathrm{i}=1}^{\mathrm{n}}\left[\operatorname{Pop}_{\mathrm{i}} \times \mathrm{f}\left(\mathrm{pcGNP}_{\mathrm{PPP}_{\mathrm{i}}}\right) / \mathrm{g}\left(\mathrm{pcCR}_{\mathrm{i}}\right)\right]}
$$

(Sagar, A.D., 2000 [31])

where $F_{i}$ is the fraction of the global emissions allocated to country $i$, and $f$ and $g$ are the functions of pcGNPPPP and pcCR, respectively.

In this research paper, Equation (11) was redefined, replacing function $g$ with another function $g^{\prime}$ that depends on the parameter $\mathrm{CE}_{2} \mathrm{~N}$. GDP was also used instead of pcGNP ${ }_{\mathrm{PPP}}$. The formula obtained after applying all those changes is as follows:

$$
F_{i N}=\frac{\text { Pop }_{\mathrm{i}} \times \mathrm{f}(\mathrm{GDP}) / \mathrm{g} /\left(\mathrm{CE}_{2} \mathrm{~N}\right)}{\sum_{\mathrm{i}=1}^{\mathrm{n}}\left[\mathrm{Pop}_{\mathrm{i}} \times \mathrm{f}(\mathrm{GDP}) / \mathrm{g} /\left(\mathrm{CE}_{2} \mathrm{~N}\right)\right]}
$$

The obtained results are presented below (Table 11).

Table 11. Sagar results vs. results with $\mathrm{CE}_{2} \mathrm{~N}$. Own elaboration.

\begin{tabular}{ccc}
\hline & Year $\mathbf{1 9 9 5}$ & \\
\hline Country & $\mathbf{F}_{\mathbf{~}} \mathbf{( \% )}$ & $\mathbf{F}_{\mathbf{i N}} \mathbf{( \% )}$ \\
\hline USA & 2.18 & 4.79 \\
Japan & 2.34 & 3.91 \\
Norway & 0.05 & 0.07 \\
France & 0.92 & 2.55 \\
Canada & 0.26 & 0.44 \\
\hline
\end{tabular}


Table 11. Cont.

\begin{tabular}{|c|c|c|}
\hline \multicolumn{3}{|c|}{ Year 1995} \\
\hline Country & $F_{i}(\%)$ & $F_{i N}(\%)$ \\
\hline Germany & 0.69 & 2.44 \\
\hline Netherlands & 0.20 & 0.31 \\
\hline Italy & 1.07 & 2.34 \\
\hline UK & 0.53 & 1.49 \\
\hline Australia & 0.17 & 0.24 \\
\hline Czech Republic & 0.04 & 0.09 \\
\hline Poland & 0.12 & 0.34 \\
\hline Russia & 0.33 & 1.35 \\
\hline Ukraine & 0.07 & 0.29 \\
\hline Singapore & 0.04 & 0.04 \\
\hline Qatar & 0.003 & 0.001 \\
\hline South Korea & 0.99 & 0.64 \\
\hline Chile & 0.43 & 0.23 \\
\hline Saudi Arabia & 0.18 & 0.42 \\
\hline Malaysia & 0.65 & 0.32 \\
\hline South Africa & 0.24 & 0.33 \\
\hline Mexico & 1.52 & 2.83 \\
\hline Brazil & 5.36 & 8.39 \\
\hline Trinidad \& Tobago & 0.004 & 0.001 \\
\hline Ecuador & 0.28 & 0.13 \\
\hline Philippines & 2.78 & 1.43 \\
\hline Kazakhstan & 0.03 & 0.05 \\
\hline Indonesia & 5.78 & 7.25 \\
\hline China & 15.30 & 9.64 \\
\hline Vanuatu & 0.008 & 0.000 \\
\hline Egypt & 1.01 & 1.50 \\
\hline Solomon Islands & 0.019 & 0.000 \\
\hline Senegal & 0.32 & 0.03 \\
\hline India & 16.71 & 21.26 \\
\hline Kenya & 0.89 & 0.39 \\
\hline Nepal & 0.89 & 0.15 \\
\hline Bangladesh & 4.54 & 3.11 \\
\hline Uganda & 0.72 & 0.10 \\
\hline Nigeria & 1.04 & 1.99 \\
\hline Burundi & 0.16 & 0.01 \\
\hline Mozambique & 0.32 & 0.02 \\
\hline Ethiopia & 1.04 & 0.43 \\
\hline
\end{tabular}

Vaillancourt and Waaub (2003)

Vaillancourt and Waaub [32] also developed a model to allocate GHG emissions that was based on equity. They defined a total of 11 criteria to allocate these emissions and gave different weights to them that depended on the level of development of the country. (South and North criteria, Table 12).

Table 12. Vaillancourt results vs. $\mathrm{CE}_{2} \mathrm{~N}$ results. Own elaboration.

\begin{tabular}{cccc}
\hline Region & North Criteria (\%) & South Criteria (\%) & CE $_{\mathbf{2}} \mathbf{N}$ Criteria (\%) \\
\hline Africa & 2.7 & 8.5 & 4.8 \\
Latin America & 2.6 & 4.2 & 5.4 \\
Asia & 1.7 & 5.3 & 8.5 \\
Australia-NZ & 0.5 & 0.7 & 1.9 \\
Canada & 1.1 & 1.1 & 2.5 \\
FSU & 6.5 & 7.3 & 8.3 \\
China & 10.2 & 24.9 & 16.3 \\
South Korea & 0.4 & 0.7 & 2.8 \\
\hline
\end{tabular}


Table 12. Cont.

\begin{tabular}{cccc}
\hline Region & North Criteria (\%) & South Criteria (\%) & CE $_{\mathbf{2}} \mathbf{N}$ Criteria (\%) \\
\hline USA & 49.7 & 23 & 13.3 \\
Eastern Europe & 1.1 & 1.7 & 3.2 \\
Western Europe & 16.8 & 9.4 & 8.3 \\
India & 1.4 & 5.8 & 7.3 \\
Japan & 2.1 & 1.9 & 4.9 \\
Mexico & 1 & 1.8 & 3.6 \\
Middle East & 2.1 & 3.7 & 8.9 \\
\hline
\end{tabular}

In this research paper, it is proposed to substitute those criteria by the parameter $\mathrm{CE}_{2} \mathrm{~N}$ and apply the same model. The model can be summed up in two main steps:

1. Definition of priority functions

$$
\begin{gathered}
a(t)=\frac{1}{a v e-\min } \\
b=1-\max (a)
\end{gathered}
$$

(Vaillancourt and Waaub, 2003, [32])

$$
n_{i}(k, t)=v_{i}(k, t) \times a(t)+b(t) \text { if } v_{i}(k, t)>\text { averagen }_{i}(k, t)=0 \text { if } v_{i}(k, t)<\text { average }
$$

(Vaillancourt and Waaub, 2003, [32])

where $v_{i}(k, t)$ is the variable; $n_{i}(k, t)$, the normalized variable; $\mathrm{i}$, the country; $\mathrm{k}$, the criteria and $t$, the year.

The priority functions are defined as:

$$
\begin{gathered}
g_{i j}(k, t)=\left(n_{i}(k, t)-n_{j}(k, t)\right) \times a^{\prime}(t)+b^{\prime}(t) \text { if } n_{i}(k, t)>n_{j}(k, t) \\
g_{i j}(k, t)=0 \text { if } n_{i}(k, t)<n_{j}(k, t)
\end{gathered}
$$

(Vaillancourt and Waaub, 2003, [32])

$$
a^{\prime}(t)=\frac{1}{p-q}
$$

(Vaillancourt and Waaub, 2003, [32])

$$
b^{\prime}(t)=a-p\left(a^{\prime}(t)\right)
$$

where $p$ and $q$ are the maximum and minimum differences between countries respectively.

Adding all the criteria considered $(k)$ :

$$
g_{i j}(t)=\sum_{k} w_{k} g_{i j}(k, t)
$$

(Vaillancourt and Waaub, 2003, [32])

where $w_{k}$ is the weight of criteria $k$

$$
f_{i j}=\left(1-\alpha_{t}\right)\left(f_{i j}(t-1)\right)+\alpha_{t} g_{i j}(t)
$$

(Vaillancourt and Waaub, 2003, [32])

where $\alpha_{t}$ varies from 1 to 0 from 2000 to 2050

Finally,

$$
x_{i j}=f_{j i}(t)-f_{i j}(t)
$$

(Vaillancourt and Waaub, 2003, [32]) 
2. $\quad$ Allocation of emissions

$$
a_{i}(t)=e_{i}(t-1) \frac{E(t)}{E(t-1)}
$$

(Vaillancourt and Waaub, 2003, [32])

where $e_{i}(t-1)$ is the previous emissions of the region and $E(t)$ is the global emissions.

$$
e_{i}(t)=a_{i}(t)\left[1+\sum_{j} \frac{a_{j}(t)}{E(t)} x_{i j}(t)\right]
$$

(Vaillancourt and Waaub, 2003, [32])

If, instead of using the 11 criteria that Vaillancourt and Waaub [32] defined, the parameter $\mathrm{CE}_{2} \mathrm{~N}$ is used as the conceptual base of the model, the allocation of $\mathrm{CO}_{2}$ emissions for the year 2020 is as follows:

\subsection{Graphs}

To have a visual knowledge of the worst countries in terms of total emissions, and emissions per capita and per GDP, "traffic lights diagrams" are presented below (Figures 2-4). Countries that have unacceptable values of any of the variables are in the red zone and those that have medium or acceptable values are in the green area. The further from the origin, the worse the position of the country.

* All the data presented in the graphs are in emissions per year

\section{- Total emissions vs. emissions per capita}

With the aim of scaling properly the graphs and making them easier to visualize, the three countries with the greatest values of total emissions and the two countries with the highest emissions per capita were removed and are not shown in the graph below.

These countries were China, the USA, EU27 + UK, Palau, and New Caledonia [71]. If they were represented, the five of them would be in the red zone.

Countries such as Australia, Canada, or South Korea that do not have high rates of total emissions are in the red zone because their emissions compared to their population are high, and they will be the countries less benefited if $\mathrm{CE}_{2} \mathrm{~N}$ is implemented in environmental models.

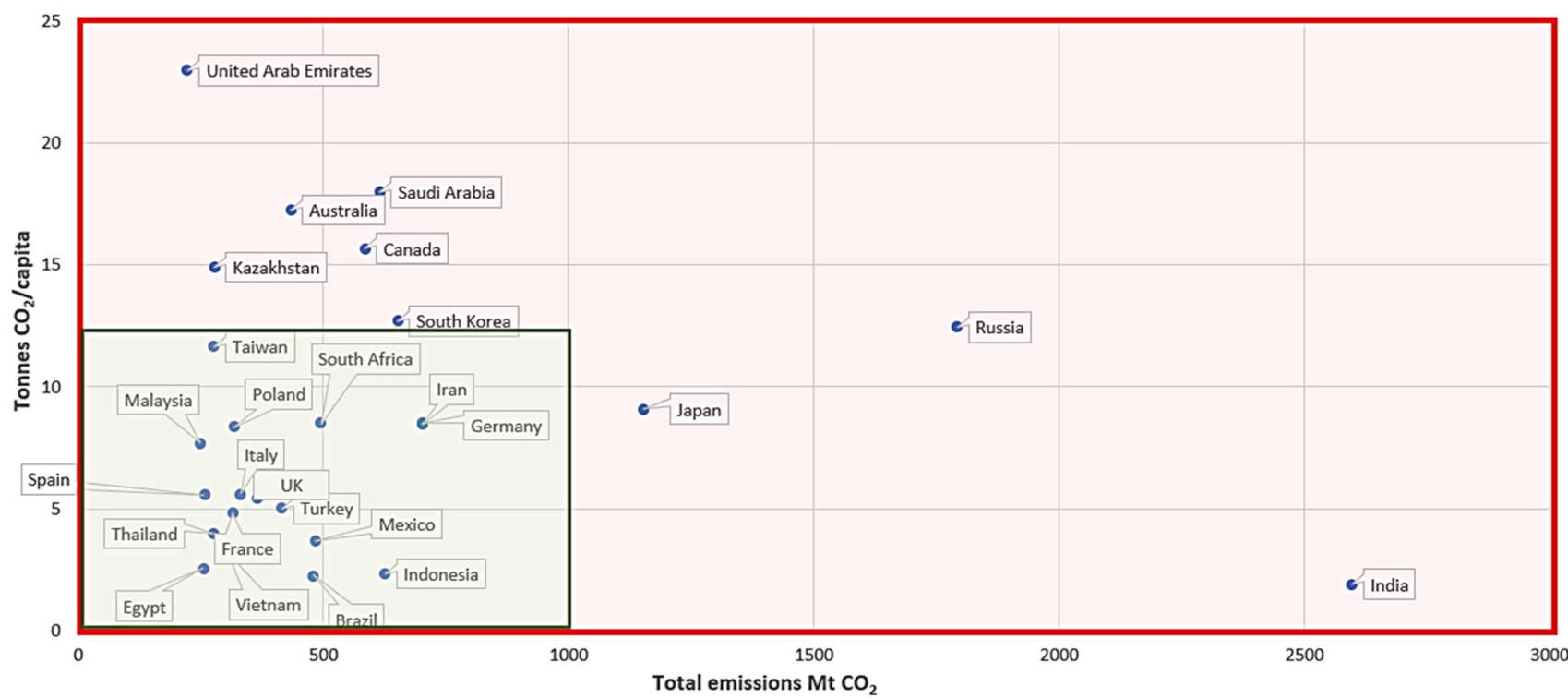

Figure 2. Traffic light diagram of the total emissions vs. emissions per capita. Own elaboration. 


\section{- Emissions per capita vs. emissions per kUSD}

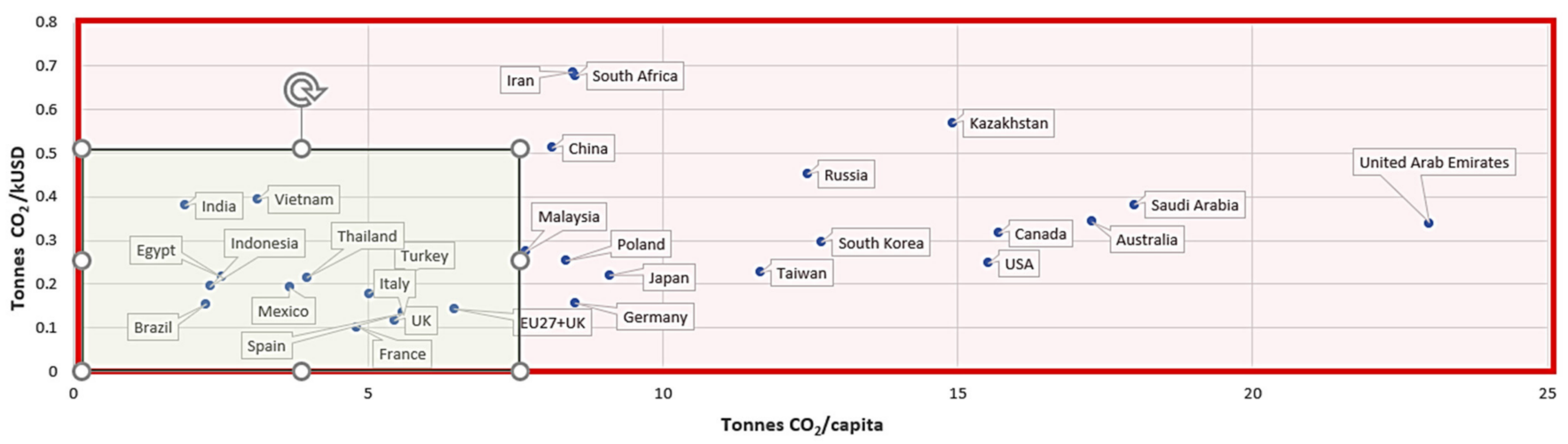

Figure 3. Traffic light diagram of the emissions per capita vs. emissions per kUSD. Own elaboration.

- Total emissions vs. emissions per kUSD

The same procedure as before was followed. China, the USA, EU27+UK, Palau, and New Caledonia were removed in order to obtain a better visualization of the graph.

As explained in Figure 2, countries with high values of emissions per GDP, such as South Africa or Iran, would be the countries most penalized.

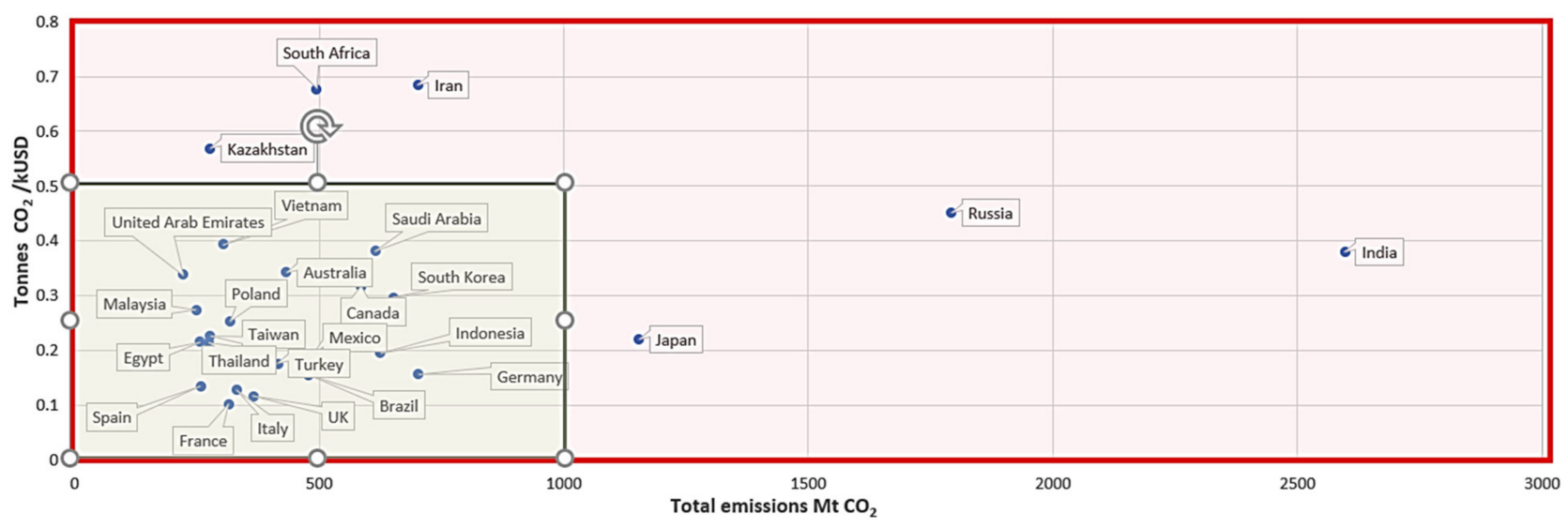

Figure 4. Traffic light diagram of total emissions vs. emissions per kUSD. Own elaboration.

\section{Discussion of Results}

From 1990 to 2019, global $\mathrm{CO}_{2}$ emissions have increased by 15,333 Mt, which is $68 \%$ more compared to those in 1990. However, the Kyoto Protocol was satisfied. This is due to the fact that the countries that had reduction targets in the Kyoto Protocol and fulfilled their promises reduced their emissions by a high percentage, but the rest of the world did not.

As stated by Zhang et al. [23] and Sagar [31], the level of emissions of a country is closely related to its industrialized level and to its level of development. Economic growth is positively related to $\mathrm{CO}_{2}$ emissions (Kim et al. [72]). Countries such as China or India that were considered as developing countries in 1990 and, therefore, did not have to fulfill any emission commitment in the Kyoto Protocol have become powerful countries and, consequently, have increased enormously their emissions. China has risen them by $480 \%$, going from being responsible for $10 \%$ of the total emissions in 1990 to $30 \%$ in 2019 , India from $2 \%$ to $7 \%$, and Iran from $0.9 \%$ to $1.8 \%$. On the other hand, annexed countries that ratified the Kyoto Protocol were responsible for $68 \%$ of emissions in 1990, but only accounted for $11 \%$ of the emissions in 2019 . Countries such as Germany, Italy, or Russia considerably reduced their emissions, but their efforts were not enough. Countries who 
were annexed to the Kyoto Protocol reduced their emissions to $72 \%$ of the base year (the initial objective was only to reduce it to $82 \%$ ), but global emissions increased by $68 \%$ with respect to those in 1990. This is clear proof that the Kyoto Protocol became outdated.

The effectiveness of the Kyoto Protocol is a very controversial topic and it is difficult to measure (Almer and Winkler [73]). Therefore, the results obtained in this research contradict some of those of previous studies, such as Grunewald and Martínez-Zarzoso [74,75], who stated that the Kyoto Protocol had a reducing effect on $\mathrm{CO}_{2}$ emissions in both developing and developed countries, and Maamoun [76], who considered the Kyoto Protocol a success. However, the results of this study are in line with the results obtained in other research: Kim et al. [72] limited the environmental benefits of the Kyoto Protocol to annexed countries, and Almer and Winkler [73] and Thakur [77] even questioned these positive effects.

With respect to the emissions per capita and emissions per kUSD, countries such as Curaçao or Palau are those with the worst values. There are two main types of countries that have high values of emissions per capita or emissions per kUSD:

- Countries with high levels of total emissions, such as China (high numerator in emissions/capita or kUSD);

- Developing countries with very low levels of production or who are poorly populated, which makes the emissions per capita or per kUSD high, even with a low level of total emissions (Palau or Curaçao). (Low denominator in emissions/capita or kUSD).

This diversity among countries with regards to the emissions per capita and per kUSD ranking could also be explained by the Environmental Kuznets Curve [50] mentioned before. This theory states that the emissions of $\mathrm{CO}_{2}$ follow an inverted U-shape with economic growth. Therefore, countries that are right now developing and that have preindustrial economies will have high rates of emissions per kUSD and usually also per capita. This is the reason why countries such as Kazakhstan, St. Pierre, and Miquelon or Bahrain appear in Tables 5 and 6. In general, the countries with the worst values of emissions efficiency are developing countries, because their economy is not efficient and implies high rates of emissions.

Focusing on the new parameter proposed, $\mathrm{CE}_{2} \mathrm{~N}$ :

The classification of the 10 most polluting countries obtained by applying the new formula $\left(\mathrm{CE}_{2} \mathrm{~N}\right)$ is very similar to the classification obtained if only total emissions are analyzed. However, from the ninth position onwards, the new estimation proposed of $\mathrm{CE}_{2} \mathrm{~N}$ differs from the classification by total emissions. The use of $\mathrm{CE}_{2} \mathrm{~N}$ allows considering the emissions per capita and emissions per kUSD at the same time as the total emissions, giving a better idea of which countries should improve their environmental policies, and showing which countries should improve either their total emissions, emissions per capita, or emissions per kUSD.

In addition, the variable $\mathrm{CE}_{2} \mathrm{~N}$ is much more elastic than the total emissions; differences in the carbon equivalent units between countries are much less than the differences in $M t$ of $\mathrm{CO}_{2}$. This means that, if $\mathrm{CE}_{2} \mathrm{~N}$ is implemented in international agreements, it could promote the development of environmental measures, as improving $\mathrm{CE}_{2} \mathrm{~N}$ values is simpler and it can be seen as more achievable than improving total emissions statistics.

The low elasticity of the 10 most emitting countries is because, as explained in Section 4.3.1, they emit huge amounts of $M t$ of GHG to the atmosphere and, consequently, the difference in the amount of gases emitted by them is large, which makes it very difficult to change their relative position in the new classification.

If this is translated to reality and policy measures, it means that, until countries such as China, the USA, or India, commit to climate change and develop real political measures to reduce their emissions, the efforts made by the rest of the countries will be useless. The obtained results are in line with those obtained in earlier studies: Paltsev et al. [78] pointed out that the participation or non-participation of China in global climate architecture can result in a $1.1^{\circ} \mathrm{C}$ to $1.3^{\circ} \mathrm{C}$ change by the end of the century. Brenton [79] and Liu et al. [80] also pointed out that the cooperation of the USA and China, as the two largest producers 
of GHG, is key to reaching sustainable development. Without the largest GHG emitters' involvement, ambitious global climate goals are vastly more difficult, if not impossible, to achieve. Only 10 countries out of 194 are responsible for more than $60 \%$ of the total $\mathrm{CO}_{2}$ emissions. China is the biggest pollutant; it is responsible for $30 \%$ of global emissions, followed by the USA, with $13 \%$, and India, with $7 \%$. Without additional policy intervention, China's $\mathrm{CO}_{2}$ emissions will continue to grow until 2040 or 2050 and will approximately double from their 2010 level (Liu et al., 2017 [80]).

$\mathrm{CE}_{2} \mathrm{~N}$ can also be used in other environmental models.

In the case of the Sagar model [31], the use of $\mathrm{CE}_{2} \mathrm{~N}$ and the removal of the historic component implies assigning more weight to the population, GDP, and emissions of a country. When allocating $\mathrm{CO}_{2}$ emissions, the model gives greater percentages to countries that have high levels of production and that are densely populated, such as Japan or Germany, and penalizes countries with high levels of emissions, such as China (See Table 11). It benefits countries with good values of emissions efficiency; the more efficient they are, the more they can emit. In addition, the definition of the historic responsibility function is not entirely clear, so substituting this function with $\mathrm{CE}_{2} \mathrm{~N}$ improves the transparency, clarity, and objectivity of the model.

In the case of the Vaillancourt model [32], the introduction of the parameter $\mathrm{CE}_{2} \mathrm{~N}$ helps to improve the clarity and objectivity of the model. Vaillancourt defined different weights and criteria that depended on the level of development of the countries and their results varied a lot depending on the criteria and weights applied. The introduction of $\mathrm{CE}_{2} \mathrm{~N}$ to the model ends the problem of the variability of the results with different criteria, unifies all these criteria, simplifies the model, and makes it more objective (see Table 12). The consequences of basing the Vaillancourt model on $\mathrm{CE}_{2} \mathrm{~N}$ are similar to the implementation of this parameter in the Sagar model; countries that have a good balance of total emissions, emissions per capita, and per GDP are benefited. Countries that have unacceptable values in any of these variables (countries in the red zone in Figures 2-4) will be penalized, and the allocation of emissions will be much less for them.

\section{Policy Recommendations}

To address climate change, every country has to cooperate and leave nationalist approaches behind. There are many articles that study the relationship between globalization and GHG emissions [56-59]. However, none of them analyzed in depth the concept of globalization; previous articles analyzed the impacts that a global economy can have on the environment, but they did not mention that only the economy is global. Politics are not global, and here is the main problem. Thanks to globalization, nowadays, society has access to many services and goods that it would not have if the economy was only local. Therefore, the current global economic model is hard to change and nor is it the solution. What should be promoted is global politics. Emissions and climate change do not have borders, so to cut emissions and tackle climate change, global politics are needed; the final objective is that every state in the world reduces its emissions and that they cooperate to face global warming. Every country should develop a realistic and affordable plan adapted to its history and situation without looking at other countries or the disadvantages with respect to other states. Moreover, international cooperation is needed to push the most polluting countries to cut their emission, even if this has a negative impact on their economy. Without the commitment of the big economies (China, the USA, India, etc.), very little can be done, as they are responsible for more than $40 \%$ of total emissions.

Climate change is a global problem and, as a global problem, it needs a global answer. Emissions from China affect the inhabitants of Australia, and global and without borders politics and cooperation are the only solution. Another difficulty is that there are many interests involved, depending on the climate variable that is analyzed, and the statistics differ a lot. The capacity of manipulating information through the media added to the economic and political interests give very different speeches that may raise questions about the reality of climate change. 
On the other hand, developed countries should help developing countries to reach their peak of emissions as soon as possible with the aim of being able to reduce their emissions as soon as possible (Environmental Kuznets Curve Theory [13,14,50-53]). They should promote technology and knowledge transfer, and help to implement the projects needed to cut emissions. Until developing countries implement sustainable policies, climate change would be hard to face. Countries such as Germany or Denmark (developed countries) have already reduced their emissions and, nowadays, developing countries have to improve.

In addition, the use of renewable energy, the enhancement of energy efficiency, and the promotion of the blue economy have been proven to help sustainable development [12-16,28,29,55-58]. Consequently, countries should focus on developing their economy from this base, avoiding policies that promote economic expansion at the price of environmental deterioration. There is a need to create policies that strike a balance between economic expansion, environmental measures, energy transition, and technology and knowledge equity.

In conclusion, climate change is a problem that can only be addressed with international cooperation, a global economy, and global politics. Effective measures can only be achieved if nationalities and ethnicities are forgotten and if nationalist approaches are left. The answer to this problem mostly relies on the most powerful countries and, until they cooperate, very little can be achieved in the climate change fight.

\section{Conclusions}

Climate change is a reality and the countries that are most affected are small island states or mountain communities that are only responsible for $0.1 \%$ of global emissions or less. All these societies could disappear in 100 years and they can do very little to stop climate change. Developed countries need to take action and mobilize all of their resources, scientific knowledge, and technology to address this problem. The first step to facing the climate change problem is to analyze global emissions with the final aim of defining a universal criterion that could be applied to all countries and is seen as fair by all countries. Until this is achieved, effective international agreements will never be reached. In addition, it is the scientific community that should be responsible for the definition of this criterion, because it is the one with the necessary knowledge.

This article has helped to tackle this problem. It has studied the distribution of GHG emissions, the effectiveness of international agreements, and defined a new universal environmental criterion, the new parameter proposed, $\mathrm{CE}_{2} \mathrm{~N}$.

The main contribution of this paper is the definition of the new environmental parameter, $\mathrm{CE}_{2} \mathrm{~N}$. There are many environmental criteria, which leads to problems in both the scientific community and society and politics. As it has been recently seen, during COP26, world leaders do not agree on which environmental criteria should rule international agreements, which prevents the understanding between countries and progress on environmental policies. On the other hand, scientific environmental model results vary a lot depending on the criteria used. In this paper, we have addressed these two problems taking the three most important environmental variables: total emissions, and emissions per capita and per GDP, and unified them in a unique and universal parameter: $\mathrm{CE}_{2} \mathrm{~N}$. The results obtained show a unique classification of the countries that can be used to implement environmental policies. This classification considers all of the environmental criteria used until now and proposes a new way to judge environmental policies in which emissions efficiency is considered. This new parameter benefits countries with average values of total emissions, and emissions per capita and per GDP (countries in the green area in the traffic diagrams presented, such as Poland, Italy, or the UK), while penalizes countries with unacceptable values of one of these variables (countries in the red area in the traffic diagrams, such as Kazakhstan or Australia). In addition, it is much more sensitive than total emissions, so improvements in environmental policies implemented by countries will have a direct impact on their $\mathrm{CE}_{2} \mathrm{~N}$ values, which can promote real environmental measures. 
Finally, the introduction of $\mathrm{CE}_{2} \mathrm{~N}$ into previous environmental models helps to increase the objectivity and clarity of the model. This paper also calls for a reflection; it points out, as a solution to climate change, a real global economy and politics, real interdisciplinary knowledge, and cooperation between social and technical disciplines.

Future research should focus on climate change equity, globalization, and the unification of environmental criteria. The results of environmental models vary a lot depending on the criteria used; this is the main reason why this research paper focuses on the development of a parameter that unifies all of these criteria in only one value. Future articles should keep studying how to define a unique criterion to quantify emissions all across the world.

Author Contributions: This paper will be included in the PhD thesis developed by Nerea Portillo at the Technical University of Madrid, Spain, and the aim of the research relates to reviewing climate change and a new proposition about it, made by the PhD candidate. All the authors contributed toward choosing data, discussion, methodology, figures, and references to provide an accurate paper. Conceptualization, N.P.J. and V.N.V.; Funding acquisition, N.P.J.; Investigation, N.P.J., V.N.V. and J.M.d.C.; Methodology, N.P.J., V.N.V. and J.M.d.C.; Writing—original draft, N.P.J.; Writing—review \& editing, N.P.J., V.N.V. and J.M.d.C. All authors have read and agreed to the published version of the manuscript.

Funding: This research received no external funding.

Conflicts of Interest: The authors declare no conflict of interest.

\section{Abbreviations}

$\begin{array}{ll}\mathrm{CDM}_{2} & \text { Clean Development Mechanism; } \\ \mathrm{CH}_{4} & \text { Methane; } \\ \mathrm{CE}_{2} \mathrm{~N} & \text { New parameter proposed, normalized } \mathrm{CO}_{2} ; \\ \mathrm{CO}_{2} & \text { Carbon dioxide; } \\ \mathrm{EC} & \text { European Commission; } \\ \mathrm{EU} & \text { European Union; } \\ \mathrm{EU} 27+\mathrm{UK} & \text { 27 members states of the European Union and United Kingdom; } \\ \mathrm{GDP} & \text { Gross Domestic Product; } \\ \mathrm{GHG} & \text { Greenhouse gas; } \\ \mathrm{IPCC} & \text { Intergovernmental Panel on Climate Change; } \\ \mathrm{JI} & \text { Joint Implementation; } \\ \text { kUSD } & \text { 1000 United States Dollars; } \\ \mathrm{Mt} & \text { Megaton; } \\ \mathrm{N} 2 \mathrm{O} & \text { Oxide of nitrogen; } \\ \text { RCP } & \text { Representative Concentration Pathways; } \\ \mathrm{SDG} & \text { Sustainable Development Goals; } \\ \mathrm{t} & \text { Tons; } \\ \mathrm{UK} & \text { United Kingdom; } \\ \mathrm{UN} & \text { United Nations; } \\ \mathrm{UNFCC} & \text { United Nations Framework Convention on Climate Change; } \\ \text { USA } & \text { United States of America; } \\ \text { WOS } & \text { Web of Science. } \\ & \end{array}$

\section{References}

1. Todorov, A.V. Reply. J. Appl. Clim. Meteorol. 1986, 25, 258-259. [CrossRef]

2. Werndl, C. On Defining Climate and Climate Change. Br. J. Philos. Sci. 2016, 67, 337-364. [CrossRef]

3. Lorenz, E. Climatic Change as a Mathematical Problem. J. Appl. Meteorol. 1970, 9, 325-329. [CrossRef]

4. Dymnikov, V.; Gritsoun, A. Atmospheric Model Attractors: Chaoticity, Quasi-Regularity and Sensitivity. Nonlinear Process. Geophys. 2001, 8, 201-208. [CrossRef]

5. UNFCCC. United Nations Framework Convention on Climate Change 1992, Article 1. Available online: https://unfccc.int/ resource/docs/convkp/conveng.pdf (accessed on 5 December 2021). 
6. IPCC. 2018: Annex I: Glossary in: Global Warming of $1.5^{\circ} \mathrm{C}$. An IPCC Special Report on the Impacts of Global Warming of $1.5^{\circ} \mathrm{C}$ above Pre-Industrial Levels and Related Global Greenhouse Gas Emission Pathways, in the Context of Strengthening the Global Response to the Threat of Climate Change, Sustainable Development, and Efforts to Eradicate Poverty; IPCC: Geneva, Switzerland, 2018; In Press.

7. Parry, M.L. The problem of climate in history-An editorial. Clim. Change 1982, 4, 107-110. [CrossRef]

8. Zizzamia, D. Climate Change in Human History: Prehistory to the Present. Environ. Hist. 2018, 23, 912-914. [CrossRef]

9. IPCC. Climate Change 2014: Synthesis Report; Cambridge University Press: Cambridge, UK, 2014; 151p.

10. United Nations General Assembly. Transforming Our World: The 2020 Agenda for Sustainable Development; United Nations General Assembly: New York, NY, USA, 2015.

11. Fonseca, L.M.; Domingues, J.P.; Dima, A.M. Mapping the Sustainable Development Goals Relationships. Sustainability 2020, 12, 3359. [CrossRef]

12. Bilan, Y.; Streimikiene, D.; Vasylieva, T.; Lyulyov, O.; Pimonenko, T.; Pavlyk, A. Linking between Renewable Energy, $\mathrm{CO}_{2}$ Emissions, and Economic Growth: Challenges for Candidates and Potential Candidates for the EU Membership. Sustainability 2019, 11, 1528. [CrossRef]

13. Zoundi, Z. $\mathrm{CO}_{2}$ Emissions, Renewable Energy and the Environmental Kuznets Curve, A Panel Cointegration Approach. Renew. Sustain. Energy Rev. 2017, 72, 1067-1075. [CrossRef]

14. Liu, X.; Zhang, S.; Bae, J. The Impact of Renewable Energy and Agriculture on Carbon Dioxide Emissions: Investigating the Environmental Kuznets Curve in Four Selected ASEAN Countries. J. Clean. Prod. 2017, 164, 1239-1247. [CrossRef]

15. Ziolo, M.; Jednak, S.; Savić, G.; Kragulj, D. Link between Energy Efficiency and Sustainable Economic and Financial Development in OECD Countries. Energies 2020, 13, 5898. [CrossRef]

16. Akaev, A.A.; Davydova, O.I. A Mathematical Description of Selected Energy Transition Scenarios in the 21st Century, Intended to Realize the Main Goals of the Paris Climate Agreement. Energies 2021, 14, 2558. [CrossRef]

17. Peña-Ramos, J.A.; del Pino-García, M.; Sánchez-Bayón, A. The Spanish Energy Transition into the EU Green Deal: Alignments and Paradoxes. Energies 2021, 14, 2535. [CrossRef]

18. Drożdż, W.; Kinelski, G.; Czarnecka, M.; Wójcik-Jurkiewicz, M.; Maroušková, A.; Zych, G. Determinants of DecarbonizationHow to Realize Sustainable and Low Carbon Cities? Energies 2021, 14, 2640. [CrossRef]

19. Zimon, D.; Tyan, J.; Sroufe, R. Drivers of Sustainable Supply Chain Management: Practices for Alignment with UN Sustainable Development Goals. Int. J. Qual. Res. 2020, 14, 219-236. [CrossRef]

20. Grossman, G.M.; Krueger, A.B. Environmental Impacts of a North American Free Trade Agreement. Natl. Bur. Econ. Res. 1991, 3914. [CrossRef]

21. Grossman, G.M.; Krueger, A. Economic Growth and the Environment. Q. J. Econ. 1995, 110, 353-377. [CrossRef]

22. Douglas, H.E.; Selden, T. Stoking the fires? $\mathrm{CO}_{2}$ Emissions and Economic Growth. J. Public Econ. 1995, 1, 85-101. [CrossRef]

23. Zhang, Z.Q.; Qu, J.S.; Zeng, J.A. Quantitative comparison and analysis on the assessment indicators of greenhouse gases emission. J. Geogr. Sci. 2008, 18, 387-399. [CrossRef]

24. Moghaddam, R.F.; Moghaddam, F.F.; Cheriet, M. A modified GHG intensity indicator: Toward a sustainable global economy based on a carbon border tax and emissions trading. Energy Policy 2013, 57, 363-380. [CrossRef]

25. Liang, S.; Qu, S.; Zhu, Z.Q.; Guan, D.B.; Xu, M. Income-Based Greenhouse Gas Emissions of Nations. Environ. Sci. Technol. 2017, 51, 346-355. [CrossRef] [PubMed]

26. Arango-Miranda, R.; Hausler, R.; Romero-Lopez, R.; Glaus, M.; Ibarra-Zavaleta, S.P. Carbon Dioxide Emissions, Energy Consumption and Economic Growth: A Comparative Empirical Study of Selected Developed and Developing Countries. "The Role of Exergy". Energies 2018, 11, 2668. [CrossRef]

27. Sun, L.; Cui, H.; Ge, Q.; Adenutsi, C.D.; Hao, X. Spatial Pattern of a Comprehensive fE Index for Provincial Carbon Emissions in China. Energies 2020, 13, 2604. [CrossRef]

28. Leitão, N.C.; Lorente, D.B. The Linkage between Economic Growth, Renewable Energy, Tourism, $\mathrm{CO}_{2}$ Emissions, and International Trade: The Evidence for the European Union. Energies 2020, 13, 4838. [CrossRef]

29. Bădîrcea, R.M.; Manta, A.G.; Florea, N.M.; Puiu, S.; Manta, L.F.; Doran, M.D. Connecting Blue Economy and Economic Growth to Climate Change: Evidence from European Union Countries. Energies 2021, 14, 4600. [CrossRef]

30. Karman, A.; Miszczuk, A.; Bronisz, U. Regional Climate Change Competitiveness-Modelling Approach. Energies 2021, 14, 3704. [CrossRef]

31. Sagar, A.D. Wealth, responsibility, and equity: Exploring an allocation framework for global GHG emissions. Clim. Change 2000, 45, 511-527. [CrossRef]

32. Vaillancourt, K.; Waaub, J.P. Equity in international greenhouse gases abatement scenarios: A multicriteria approach. Eur. J. Oper. Res. 2004, 153, 489-505. [CrossRef]

33. Markandya, A. Equity and Distributional Implications of Climate Change. World Dev. 2011, 39, 1051-1060. [CrossRef]

34. Mattoo, A.; Subramanian, A. Equity in Climate Change: An Analytical Review. World Dev. 2012, 40, 1083-1097. [CrossRef]

35. Remuzgo, L.; Trueba, C.; Sarabia, J.M. Evolution of the global inequality in greenhouse gases emissions using multidimensional generalized entropy measures. Phys. A-Stat. Mech. Its Appl. 2016, 444, 146-157. [CrossRef]

36. Alcaraz, O.; Buenestado, P.; Escribano, B.; Sureda, B.; Turon, A.; Xercavins, J. Distributing the Global Carbon Budget with climate justice criteria. Clim. Change 2018, 149, 131-145. [CrossRef] 
37. Alcaraz, O.; Sureda, B.; Turon, A.; Ramírez, C.; Gebellí, M. Equitable mitigation to achieve the $1.5^{\circ} \mathrm{C}$ goal in the Mediterranean Basin. Clim. Change 2021, 165, 62. [CrossRef]

38. Jena, P.R.; Managi, S.; Majhi, B. Forecasting the $\mathrm{CO}_{2}$ Emissions at the Global Level: A Multilayer Artificial Neural Network Modelling. Energies 2021, 14, 6336. [CrossRef]

39. Dubash, N.K. Toward a Progressive Indian and Global Climate Politics. New Delhi: Centre for Policy Research Climate Initiative 2009, Working Paper. Available online: https://cprindia.org/workingpapers/toward-a-progressive-indian-and-global-climatepolitics / (accessed on 22 March 2021).

40. Saran, S. Global governance and climate change. Glob. Gov. Rev. Multilater. Int. Inst. 2009, 15, 457-460. [CrossRef]

41. Campbell-Lendrum, D.; Corvalan, C. Climate Change and Developing-Country Cities: Implications for Environmental Health and Equity. J. Urban Health-Bull. N. Y. Acad. Med. 2007, 84, I109-I117. [CrossRef]

42. Baležentis, T.; Liobikienè, G.; Štreimikienè, D.; Sun, K. The impact of income inequality on consumption-based greenhouse gas emissions at the global level: A partially linear approach. J. Environ. Manag. 2020, 267, 110635. [CrossRef]

43. Formetta, G.; Feyen, L. Empirical evidence of declining global vulnerability to climate-related hazards. Glob. Environ. Change 2019, 57, 101920. [CrossRef]

44. Cao, J. Reconciling Human Development and Climate Protection: Perspectives from Developing Countries On Post-2012 International Climate Change Policy. Harvard Kennedy School of Government Discussion Paper 08-25. Harvard University: Cambridge, MA, USA. Available online: http:/ / belfercenter.ksg.harvard.edu/publication/18685/ (accessed on 24 March 2021).

45. Cooper, R.N. The Case for Charges on Greenhouse Gas Emissions. Massachusetts: Cambridge, Massachusetts, USA: Harvard Project on Climate Agreements. 2008. Available online: https:/ /heep.hks.harvard.edu/publications/case-charges-greenhousegas-emissions-0 (accessed on 24 March 2021).

46. Stern, N. The Global Deal. Climate Change and the Creation of a New Era of Progress and Prosperity; Public Affairs: New York, NY, USA, 2009; ISBN 978-1433265365.

47. Kanitkar, T.; Jayaraman, T.; D'Souza, M.; Purkayastha, P. Carbon budgets for climate change mitigation-A GAMS-based emissions model. Curr. Sci. 2013, 104, 1200-1206. Available online: https://www.researchgate.net/publication/281229901_ Carbon_budgets_for_climate_change_mitigation_-_a_GAMS-based_emissions_model (accessed on 26 March 2021).

48. Shue, H. The International Politics of the Environment: Actors, Interests, and Institutions; Hurrell, A., Kingsbury, B., Eds.; Clarendon Press: Oxford, UK, 1992; pp. 373-397. ISBN 9780198273653.

49. Falkner, R. The unavoidability of justice-And order-In international climate politics: From Kyoto to Paris and beyond. Br. J. Politics Int. Relat. 2019, 21, 270-278. [CrossRef]

50. Stern, D.I. The Environmental Kuznets Curve; International Society for Ecological Economics Internet Encyclopaedia of Ecological Economics: Boston, MA, USA, 2003.

51. Dogan, E.; Inglesi-Lotz, R. The impact of Economic Structure to Environmental Kuznets Curve (EKC) Hypothesis: Evidence from European Countries. Environ. Sci. Pollut. Res. 2020, 27, 12717-12724. [CrossRef] [PubMed]

52. Mania, E. Export Diversification and $\mathrm{CO}_{2}$ Emissions: An Augmented Environmental Kuznets Curve. J. Int. Dev. 2020, $32,168-185$. [CrossRef]

53. Jóźwik, B.; Gavryshkiv, A.-V.; Kyophilavong, P.; Gruszecki, L.E. Revisiting the Environmental Kuznets Curve Hypothesis: A Case of Central Europe. Energies 2021, 14, 3415. [CrossRef]

54. Knight, K.W.; Schor, J.B. Economic Growth and Climate Change: A Cross-National Analysis of Territorial and Consumption-Based Carbon Emissions in High-Income Countries. Sustainability 2014, 6, 3722-3731. [CrossRef]

55. Rahman, M.M. Environmental degradation: The role of electricity consumption, economic growth, and globalization. J. Environ. Manag. 2020, 253, 109742. [CrossRef]

56. Villanthenkodath, M.A.; Ansari, M.A.; Shahbaz, M.; Vo, X.V. Do tourism development and structural change promote environmental quality? Evidence from India. Environ. Dev. Sustain. 2021, 4, 1-32. [CrossRef]

57. Baydoun, H.; Aga, M. The Effect of Energy Consumption and Economic Growth on Environmental Sustainability in the GCC Countries: Does Financial Development Matter? Energies 2021, 14, 5897. [CrossRef]

58. Pata, U.K. Linking renewable energy, globalization, agriculture, $\mathrm{CO}_{2}$ emissions and ecological footprint in BRIC countries: A sustainability perspective. Renew. Energy 2021, 173, 197-208. [CrossRef]

59. Kihombo, S.; Ahmed, Z.; Chen, S.; Adebayo, T.S.; Kirikkaleli, D. Linking financial development, economic growth, and ecological footprint: What is the role of technological innovation? Environ. Sci. Pollut. Res. 2021, 28, 61235-61245. [CrossRef]

60. Xu, Z.; Baloch, M.A.; Danish Meng, F.; Zhang, J.; Mahmood, Z. Nexus between financial development and $\mathrm{CO}_{2}$ emissions in Saudi Arabia: Analyzing the role of globalization. Environ. Sci. Pollut Res. 2018, 25, 28378-28390. [CrossRef]

61. Salahuddin, M.; Alam, K.; Ozturk, I.; Sohag, K. The effects of electricity consumption, economic growth, financial development and foreign direct investment on $\mathrm{CO}_{2}$ emissions in Kuwait. Renew. Sustain. Energy Rev. 2018, 81, 2002-2010. [CrossRef]

62. Chebbi, H.E. Long and Short-Run Linkages between Economic Growth, Energy Consumption and $\mathrm{CO}_{2}$ Emissions in Tunisia. Middle East Dev. J. 2010, 2, 139-158. [CrossRef]

63. Jiang, C.; Ma, X. The Impact of Financial Development on Carbon Emissions: A Global Perspective. Sustainability 2019, $11,5241$. [CrossRef]

64. Ameyaw, B.; Yao, L. Analyzing the Impact of GDP on $\mathrm{CO}_{2}$ Emissions and Forecasting Africa's Total $\mathrm{CO}_{2}$ Emissions with Non-Assumption Driven Bidirectional Long Short-Term Memory. Sustainability 2018, 10, 3110. [CrossRef] 
65. Naciones Unidas. Convención Marco de las Naciones Unidas Sobre el Cambio Climático; Naciones Unidas: New York, NY, USA, 1992; $25 \mathrm{p}$.

66. Ministerio Para la Transición Ecológica y el Reto Demográfico. Protocolo de Kioto. Available online: https://www.miteco.gob.es / es/ (accessed on 20 January 2021).

67. UNFCC. Doha Climate Change Conference-November 2012. Available online: https://unfccc.int/process-and-meetings/ conferences / past-conferences / doha-climate-change-conference-november-2012/doha-climate-change-conference-november2012 (accessed on 24 January 2021).

68. Ministerio Para la Transición Ecológica y el reto Demográfico. Acuerdo de París. Available online: https://www.miteco.gob es/es/cambio-climatico/temas/el-proceso-internacional-de-lucha-contra-el-cambio-climatico/naciones-unidas/elmentosacuerdo-paris.aspx (accessed on 31 January 2021).

69. UNFCC. The Clean Development Mechanism. The Clean Development Mechanism / UNFCCC. Available online: https://unfccc. int/sites/default/files/resource/UNFCCC_CDM_report_2018.pdf (accessed on 22 January 2021).

70. UNFCC. Joint Implementation. Joint Implementation / UNFCCC. Available online: https://unfccc.int/process/the-kyotoprotocol/mechanisms/joint-implementation (accessed on 22 January 2021).

71. Crippa, M.; Guizzardi, D.; Muntean, M.; Schaaf, E.; Solazzo, E.; Monforti-Ferrario, F.; Olivier, J.G.J.; Vignati, E. Fossil CO 2 Emissions of All World Countries-2020 Report, EUR 30358 EN; Publications Office of the European Union: Luxembourg, 2020; ISBN 978-92-76-21515-8. [CrossRef]

72. Kim, Y.; Tanaka, K.; Matsuoka, S. Environmental and economic effectiveness of the Kyoto Protocol. PLoS ONE 2020, 15, e0236299. [CrossRef]

73. Almer, C.; Winkler, R. Analyzing the effectiveness of international environmental policies: The case of the Kyoto Protocol. J. Environ. Econ. Manag. 2017, 82, 125-151. [CrossRef]

74. Grunewald, N.; Martínez-Zarzoso, I. Carbon dioxide emissions, economic growth and the impact of the Kyoto Protocol. In Working Paper for Spanish Ministry of Education and Science; Spanish Ministry of Education and Science: Madrid, Spain, 2011; pp $1-26$.

75. Grunewald, N.; Martinez-Zarzoso, I. Did the Kyoto Protocol fail? An evaluation of the effect of the Kyoto Protocol on $\mathrm{CO}_{2}$ emissions. Environ. Dev. Econ. 2016, 21, 1-22. [CrossRef]

76. Maamoun, N. The Kyoto protocol: Empirical evidence of a hidden success. J. Environ. Econ. Manag. 2019, 95, 227-256. [CrossRef]

77. Thakur, S. From Kyoto to Paris and Beyond: The Emerging Politics of Climate Change. India Q. 2021, 77, 366-383. [CrossRef]

78. Paltsev, S.; Morris, J.; Cai, Y.; Karplus, V.; Jacoby, H. The role of China in mitigating climate change. Energy Econ. 2012, 34, S444-S450. [CrossRef]

79. Brenton, S.A. 'Great Powers' in climate politics. Clim. Policy 2013, 13, 541-546. [CrossRef]

80. Liu, Q.; Gu, A.; Teng, F.; Song, R.; Chen, Y. Peaking China's $\mathrm{CO}_{2}$ Emissions: Trends to 2030 and Mitigation Potential. Energies 2017, 10, 209. [CrossRef] 